\title{
Root water compensation sustains transpiration rates in an Australian woodland
}

\author{
Parikshit Verma ${ }^{\mathrm{a}, \mathrm{b}}$, Steven P. Loheide $\mathrm{II}^{\mathrm{c}}$, Derek Eamus ${ }^{\mathrm{d}, \mathrm{b}}$, Edoardo \\ Daly $^{\mathrm{a}, \mathrm{b}, *}$ \\ ${ }^{a}$ Department of Civil Engineering, Monash University, Clayton, Australia \\ ${ }^{b}$ National Centre for Groundwater Research and Training, Flinders University, Adelaide, \\ Australia \\ ${ }^{c}$ Department of Civil Engineering, University of Wisconsin-Madison, Wisconsin, USA \\ ${ }^{d}$ Climate Change Cluster and School of the Environment, University of Technology, \\ Sydney
}

\begin{abstract}
We apply a model of root-water uptake to a woodland in Australia to examine the regulation of transpiration by root water compensation (i.e., the ability of roots to regulate root water uptake from different part of soil depending on local moisture availability). We model soil water movement using the Richards equation and water flow in the xylem with Darcy's equation. These two equations are coupled by a term that governs the exchange of water between soil and root xylem as a function of the difference in water potential between the two. The model is able to reproduce measured diurnal patterns of sap flux and results in leaf water potentials that are consistent with field observations. The model shows that root water compensation is a key process to allow for sustained rates of transpiration across several months. Scenarios with different root depths showed the importance of having a root system deeper than about $2 \mathrm{~m}$ to achieve the measured transpiration rates
\end{abstract}

*edoardo.daly@monash.edu 
without reducing the leaf water potential to levels inconsistent with field measurements. The model suggests that the presence of more than $5 \%$ of the root system below $0.6 \mathrm{~m}$ allows trees to maintain sustained transpiration rates keeping leaf water potential levels within the range observed in the field. According to the model, a large contribution to transpiration in dry periods was provided by the roots below $0.3 \mathrm{~m}$, even though the percentage of roots at these depths was less than $40 \%$ in all scenarios.

Keywords: root water compensation, transpiration, hydrological modeling, eco-hydrology

\section{Introduction}

Water taken up by plant roots for transpiration constitutes a significant portion of the hydrological cycle, largely determining the exchange of water, carbon and energy between the land surface and the atmosphere [1]. The accurate prediction of root water uptake is thus important in hydrological and climatological applications.

Mechanisms associated with root water uptake that have been observed in the field and have received recently renewed interest are hydraulic redistribution and root water compensation $[2,3,4,5,6,7,8,9]$. Hydraulic redistribution refers to the movement of water from soil layers with higher soil water potential to those with lower soil water potential through the root system, while root water compensation refers to the ability of plants to adjust their distribution of uptake of water through the soil profile as a function of local soil water content [10]. These passive mechanisms of root water uptake and release are key drivers in regulating water use by vegetation, becom- 
ing especially important in shallow groundwater environments [11] or duplex soils, where deeper soil layers experience large soil water potential (i.e., near saturation) when compared to the soil near the surface [12].

These two mechanisms have been discussed separately in the literature, with hydraulic redistribution being associated with an imbalance in water potentials across the root system, and root water compensation being interpreted as a defensive mechanism against water stress [13]. Recently, the definition of these two mechanisms has been merged, by acknowledging their common driving force, i.e., the non uniform water potential distribution across the root system $[14,15]$. Despite their possible different definitions, it is now recognized that the inclusion of these mechanisms in mathematical models is recommended to accurately describe root water uptake [15].

Most of the available models commonly used in hydrological applications describe root water uptake as a sink term in the Richards equation for soilwater flow, and the rate of water extraction at different depths depends on the amount of water available in the soil, the fraction of total roots present in different soil layers and the potential rate at which plant can extract water under unstressed conditions $[16,17,18]$. Root water compensation has been embedded in the sink term by using formulations to increase water uptake from wetter parts of the root system to compensate lower water uptake from roots in drier parts of the soil $[13,19,20,21,18]$. Other models relate root water uptake to root water potential; some assume a defined root water potential distribution across the soil $[22,23,10,24,25]$ and others also model water flow through the root xylem [26, 27, 28, 29]. Root water uptake is commonly assumed to depend on the difference between soil and root water 
potential. Other formulations are available. For example, van Lier et al. [30] expressed water uptake as a function of the difference between the flux matric potential in the soil and the rhizosphere. This approach has been also used to give a mechanistic interpretation of some of the earlier, empirical definitions of root water compensation [31]. More sophisticated models also consider root [32] or whole plant hydraulic architecture [33, 34, 35, 14]. Although these models permit a more detailed description of the soil water dynamics, they are computationally demanding and require a large number of parameters, some of which difficult to measure.

In this study we use a model that couples water flow in soil to the flow in the xylem of vegetation, both below and above ground. The model builds on that presented by Amenu and Kumar [27]. We use this model to show the key role of root water compensation in modulating transpiration in a woodland growing on a duplex soil. Specifically, we show i) that root water compensation is able to explain the sustained transpiration rates observed across several relatively dry months and ii) how the trees partition their water demand from various soil layers under scenarios with different root depths.

\section{Model description}

We used a one-dimensional model, thereby taking a big-leaf approximation, according to which spatial variability of the canopy is aggregated in the value of parameters estimated at the stand level. The model describes water flow in the soil and xylem, both below and above ground, with the exchange of water between soil and roots dependent on the water potential difference between the two. 
Water flow in variably saturated soils is described using the Richards equation with a sink term for root water uptake:

$$
\frac{\partial \theta}{\partial h_{s}} \frac{\partial h_{s}}{\partial t}-\frac{\partial}{\partial z}\left[k\left(h_{s}\right)\left(\frac{\partial h_{s}}{\partial z}+1\right)\right]=k_{s r}(z) f(\theta)\left(h_{x}-h_{s}\right)
$$

where $\theta\left[L^{3} L^{-3}\right]$ is volumetric water content, $h_{s}[L]$ is the pressure head in the soil, $k\left[L T^{-1}\right]$ is soil hydraulic conductivity, $z[L]$ is the vertical coordinate (positive upwards), $k_{s r}\left[L^{-1} T^{-1}\right]$ is the soil-root conductance, $f(\theta)[-]$ is a water-stress function reducing root water uptake, and $h_{x}[L]$ is the pressure head in the root xylem. We use the relationship given by van Genuchten [36] to relate $h_{s}$ to $k$ and $\theta$ (Appendix A).

Since the exchange of water between soil and roots in different soil layers depends on the amount of roots present in those layers, the parameter $k_{s r}$ is modeled as a function of root density distribution as:

$$
k_{s r}(z)=\frac{r(z)}{\int_{-d}^{0} r(z) d z} k_{s r t}
$$

where $k_{s r t}\left[T^{-1}\right]$ is total soil-to-root radial conductance, $r(z)$ is the root mass distribution as a function of depth, and $d$ is root depth. The function $r(z)$ is assumed as [16]:

$$
r(z)=\left(1-\frac{|z|}{d}\right) \exp \left(\frac{-q_{z}}{d}|z|\right) \quad-d \leq z \leq 0
$$

where $q_{z}[-]$ is an empirical parameter expressing the decrease of the root mass with depth. 
The rate of root water uptake reduces in low soil moisture conditions. Additionally, when soil becomes dry, an air gap forms between soil and roots, thereby decreasing conductivity between the two. To model this reduction in soil-root conductance, we use the function [37]:

$$
f(\theta)=\left\{\begin{array}{cc}
0 & \theta \leq \theta_{1}, \\
\left(\theta-\theta_{1}\right) /\left(\theta_{2}-\theta_{1}\right) & \theta_{1}<\theta \leq \theta_{2}, \\
1 & \theta>\theta_{2}
\end{array}\right.
$$

where $\theta_{1}$ is the volumetric soil moisture content below which root water uptake ceases, and $\theta_{2}$ represents the volumetric soil moisture content below which root water uptake starts decreasing. We did not consider any reduction in root water uptake due to oxygen stress.

In relation to vegetation, we consider above- and below-ground xylem as a porous medium and thus describe flow of water through the xylem using Darcy's equation. Below ground, flow is described by:

$$
\rho g S_{s}\left(\frac{\partial h_{x}}{\partial t}\right)-\frac{\partial}{\partial z}\left[k_{p}\left(h_{x}\right)\left(\frac{\partial h_{x}}{\partial z}+1\right)\right]=k_{s r}(z) f(\theta)\left(h_{s}-h_{x}\right)
$$

where $h_{x}[L]$ is the xylem pressure head, $S_{s}\left[M^{-1} L T^{2}\right]$ is storage within the xylem, and $k_{p}\left[L T^{-1}\right]$ is the spatially averaged axial hydraulic conductivity of the xylem.

Above ground, flow through the xylem is driven by:

$$
\rho g S_{s}\left(\frac{\partial h_{x}}{\partial t}\right)-\frac{\partial}{\partial z}\left[k_{p}\left(h_{x}\right) \frac{A_{x}}{A_{s}}\left(\frac{\partial h_{x}}{\partial z}+1\right)\right]=0
$$


where $A_{x}$ is the average xylem cross-sectional area of all the plants present in the ground area $A_{s}$. Plants are assumed to transpire only from the top of the canopy so that there are no sinks along the above-ground xylem; transpiration is a function of solar radiation, air temperature, vapor pressure deficit, and leaf water potential, as explained in Appendix B. A detailed derivation of Eq. (6) is presented in Appendix C.

Xylem conductivity, $k_{p}$, is a function of xylem potential, according to [38]:

$$
k_{p}=k_{p \max }\left(1-\frac{1}{1+\exp \left(a_{p}\left(\rho g h_{x}-b_{p}\right)\right)}\right) .
$$

Although in general $k_{p}$ can be different for below- and above-ground xylem [34], we assumed here a single value for $k_{p}$ in Eqs. (5) and (6).

\section{Case study}

The data reported here have been presented and analyzed in previous studies $[12,39,40,41,42,43]$. We refer the reader to these studies for more complete details on the site. Only a brief description of the site and data used in our analysis is given here.

\subsection{Site Description}

The site is located at latitude $33^{\circ} 39^{\prime} 41^{\prime \prime} \mathrm{S}$ and longitude $150^{\circ} 46^{\prime} 57^{\prime \prime} \mathrm{E}$ in New South Wales, Australia. The nearest weather station with rainfall and temperature data is located at the Royal Australian Air Force base in Richmond (Australian Bureau of Meteorology, station 067105). The long term statistics $(1993$ - 2013) show that the average daily minimum and maximum 

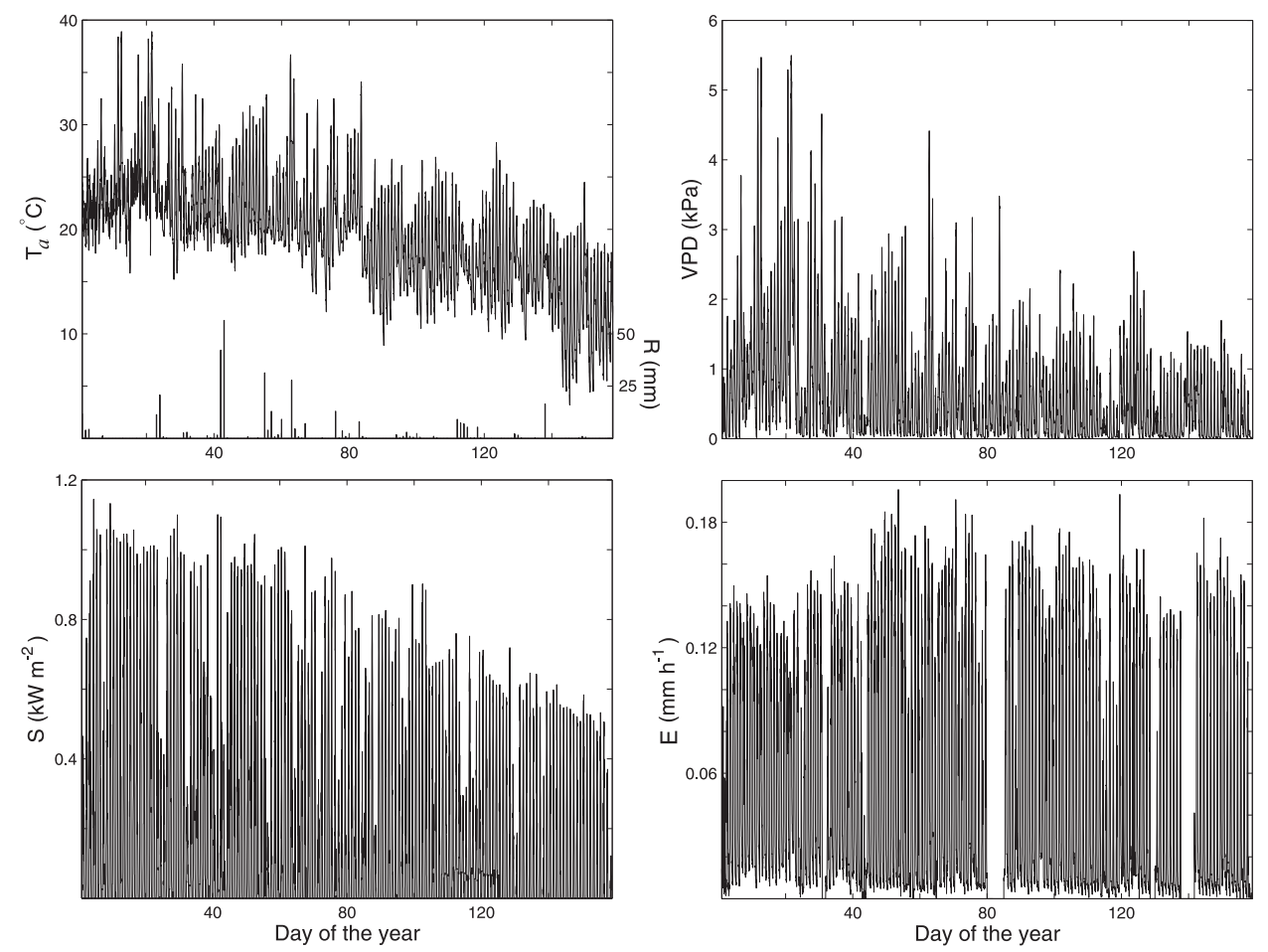

Figure 1: Observed air temperature $\left(T_{a}\right)$ and rainfall $(\mathrm{R})$, solar radiation $(\mathrm{S})$, vapor pressure deficit (VPD), and sap flux (E) between January $1^{\text {st }}$ and June $7^{\text {th }}, 2007$.

temperatures are $10^{\circ} \mathrm{C}$ and $24^{\circ} \mathrm{C}$, with January being the hottest month (average minimum and maximum temperatures are $18^{\circ} \mathrm{C}$ and $30^{\circ} \mathrm{C}$ ) and July the coldest (average daily minimum and maximum temperatures are $4{ }^{\circ} \mathrm{C}$ and $17^{\circ} \mathrm{C}$ ). Mean annual rainfall is about $730 \mathrm{~mm}$ and the wettest month is February with average rainfall of about $125 \mathrm{~mm}$.

Rainfall, solar radiation, air temperature and humidity were measured at the field site using a weather station; data from January $1^{\text {st }}$ to June $4^{\text {th }}$ in 2007 were available for this study (Figure 1). Total rainfall in this period was about $500 \mathrm{~mm}$.

The soil consists of two layers: the first is dominated by sand (sand to 
loamy sand) up to a depth of $0.8 \mathrm{~m}$, and the second is clay with a low amount of sand. The hydraulic properties for these soil types are reported in [40] and values of the parameters used in the model are listed in Table 1.

The vegetation is primarily dominated by Eucalyptus parramattensis C.A. Hall (Parramatta Red Gum) and Angophora bakeri E.C. Hall (narrow-leaved apple). The trees are about $14 \mathrm{~m}$ tall. Leaf area index (LAI) was estimated between 1.3 to 1.9. Root biomass distribution was estimated from trenches, with root masses determined up to a depth of $1.5 \mathrm{~m}$. The root biomass in the first $0.4 \mathrm{~m}$ varied between $40 \%$ and $80 \%$ of the total root biomass, according to measurements in four trenches [40]; an estimate of root distribution from these measurements is reported in Appendix D. Sap flux data were collected using the heat ratio technique at half-hour intervals (Figure 1); sensors were installed at about $1.3 \mathrm{~m}$ from the ground. Details on the sap flux measurements, including number of monitored trees, number of sensors per tree, corrections associated with wounding, estimation of zero flow, and scaling from trees to stand, are reported in Zeppel et al. [12] and [39]. Gaps in the sap-flux measurements totaled 13 days. Discrete measurements of leaf water potential and soil moisture profiles to a depth of $5 \mathrm{~m}$, spanning the two-year period 2007 - 2009, are reported in Zeppel et al. [12] and Yunusa et al. [42] respectively. These soil moisture measurements were used to parameterize the model, whereas the leaf water potential and fine scale measurements of sap flux were used to evaluate the model performance.

\subsection{Numerical simulations}

COMSOL Multiphysics (Ver. 4.1; http://www.comsol.com/) was used to solve the system of partial differential equations. 
Table 1: List of soil parameters

\begin{tabular}{|c|c|c|c|c|c|}
\hline Parameters & Units & Sand & Clay & Description & Reference \\
\hline $\begin{array}{l}\text { Measured } \\
k_{s}\end{array}$ & $\mathrm{~m} \cdot \mathrm{s}^{-1}$ & $3.45 \cdot 10^{-5}$ & $1.94 \cdot 10^{-7}$ & Saturated hydraulic conductivity & {$[40]$} \\
\hline From literature & & & & & \\
\hline$\theta_{s}$ & - & 0.47 & 0.55 & Saturated volumetric soil moisture content & {$[44]$} \\
\hline$\theta_{r}$ & - & 0.045 & 0.068 & Residual volumetric soil moisture content & {$[44]$} \\
\hline$\alpha$ & $\mathrm{m}^{-1}$ & 14.5 & 0.8 & Soil hydraulic parameter & {$[44]$} \\
\hline$n$ & - & 2.4 & 1.5 & Soil hydraulic parameter & {$[44]$} \\
\hline$l$ & - & 0.5 & 0.5 & Soil hydraulic parameter & {$[44]$} \\
\hline$\theta_{1}$ & - & 0.05 & 0.08 & Wilting point & {$[44]$} \\
\hline $\begin{array}{l}\text { Estimated } \\
\theta_{2}\end{array}$ & - & 0.09 & 0.12 & Root water uptake reduction parameter & \\
\hline
\end{tabular}

Table 2: List of vegetation parameters

\begin{tabular}{|c|c|c|c|c|}
\hline Parameter & Units & Value & Description & Reference \\
\hline $\begin{array}{l}\text { Measured } \\
A_{x} / A_{s} \\
L A I \\
q_{z}\end{array}$ & $\begin{array}{l}- \\
- \\
-\end{array}$ & $\begin{array}{c}8.62 \cdot 10^{-4} \\
1.5 \\
9\end{array}$ & $\begin{array}{c}\text { Xylem cross-sectional area and site surface ratio } \\
\text { Leaf area index } \\
\text { Root distribution parameter }\end{array}$ & $\begin{array}{l}{[43]} \\
{[12]} \\
{[40]}\end{array}$ \\
\hline $\begin{array}{l}\text { From literature } \\
a_{p} \\
b_{p} \\
C_{p} \\
g_{b} \\
g_{a} \\
k_{p \max } \\
k_{r} \\
k_{t} \\
\lambda \\
\gamma \\
\end{array}$ & \begin{tabular}{|c|}
$\mathrm{Pa}^{-1}$ \\
$\mathrm{~Pa}$ \\
$\mathrm{~J} \cdot \mathrm{m}^{-3} \cdot \mathrm{K}^{-1}$ \\
$\mathrm{~m} \cdot \mathrm{s}^{-1}$ \\
$\mathrm{~m} \cdot \mathrm{s}^{-1}$ \\
$\mathrm{~m} \cdot \mathrm{s}^{-1}$ \\
$\mathrm{~m}^{2} \cdot \mathrm{W}^{-1}$ \\
$\mathrm{~K}^{-2}$ \\
$\mathrm{~J} \cdot \mathrm{m}^{-3}$ \\
$\mathrm{~Pa} \cdot \mathrm{K}^{-1}$
\end{tabular} & $\begin{array}{c}2 \cdot 10^{-6} \\
-1.5 \cdot 10^{6} \\
1200 \\
2 . \cdot 10^{-2} \\
2 \cdot \cdot 10^{-2} \\
1 \cdot 10^{-5} \\
5 \cdot 10^{-3} \\
1.6 \cdot 10^{-3} \\
2.51 \cdot 10^{9} \\
66.7\end{array}$ & $\begin{array}{c}\text { Xylem cavitation parameter } \\
\text { Xylem cavitation parameter } \\
\text { Heat capacity of air } \\
\text { Leaf boundary layer conductance } \\
\text { Aerodynamic conductance } \\
\text { Xylem conductivity } \\
\text { Jarvis radiation parameter } \\
\text { Jarvis temperature parameter } \\
\text { Latent heat of vaporization } \\
\text { Psychrometric constant }\end{array}$ & $\begin{array}{l}{[45,38]} \\
{[45,38]} \\
{[27]} \\
{[46]} \\
{[46]} \\
{[38,47]} \\
{[46]} \\
{[46]} \\
{[27]} \\
{[27]}\end{array}$ \\
\hline $\begin{array}{l}\text { Estimated } \\
g_{\text {smax }} \\
h_{x 50} \\
k_{d} \\
k_{s r t} \\
n_{l} \\
S_{s} \\
T_{o p t}\end{array}$ & $\begin{array}{l}\mathrm{m} \cdot \mathrm{s}^{-1} \\
\mathrm{~m} \\
\mathrm{~Pa}^{-1} \\
\mathrm{~s}^{-1} \\
- \\
\mathrm{Pa}^{-1} \\
\mathrm{~K}\end{array}$ & $\mid \begin{array}{c}10 \cdot 10^{-3} \\
-130 \\
1.1 \cdot 10^{-3} \\
7.2 \cdot 10^{-10} \\
2 \\
1.1 \cdot 10^{-11} \\
289.15\end{array}$ & $\begin{array}{c}\text { Maximum leaf stomatal conductance } \\
\text { Jarvis leaf water potential parameter } \\
\text { Jarvis vapor pressure deficit parameter } \\
\text { Total soil-to-root radial conductance } \\
\text { Jarvis leaf water potential parameter } \\
\text { Xylem storage } \\
\text { Jarvis temperature parameter }\end{array}$ & \\
\hline
\end{tabular}




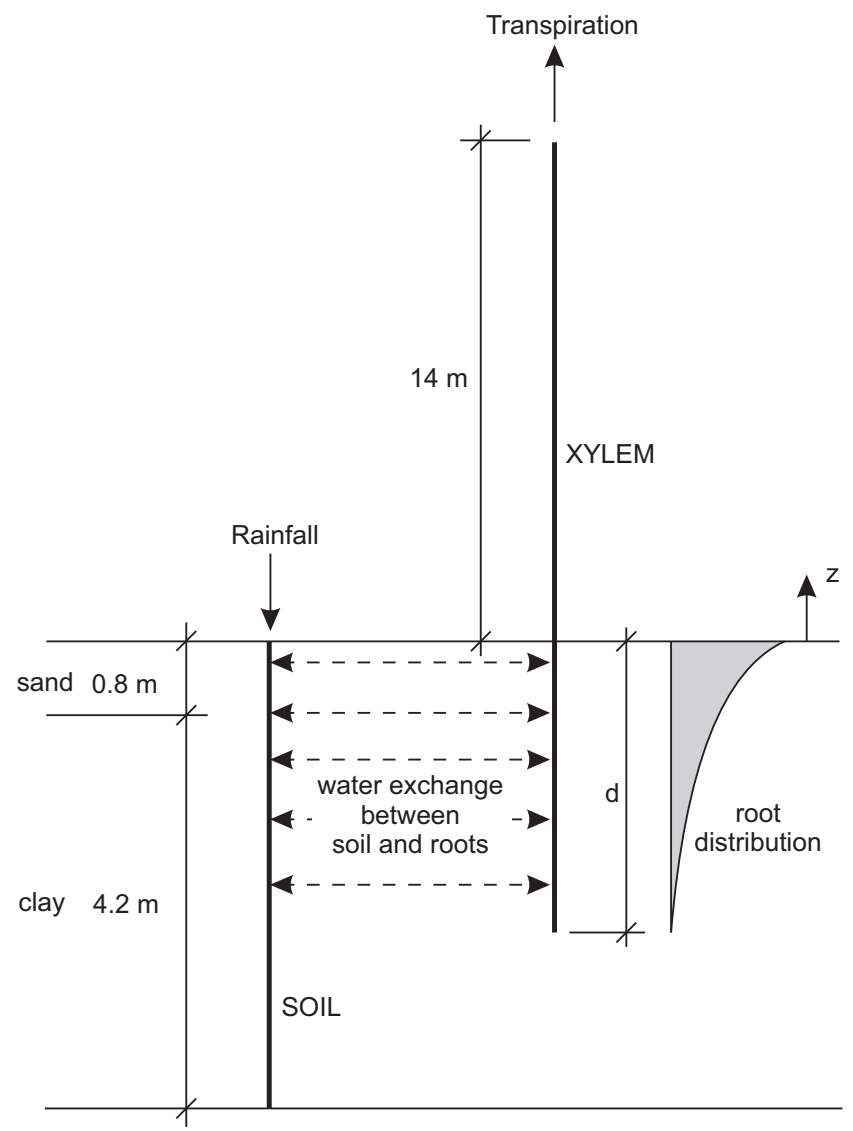

Figure 2: Schematic diagram of the setting used in the simulations. 
Figure 2 shows a schematic of the soil and the plant domains as well as the physical dimensions used in the simulations. Based on available data $[12,39,40,41,42,43]$, we used a soil profile consisting of a sand layer of $0.8 \mathrm{~m}$ above a clay layer of $4.2 \mathrm{~m}$. The water retention and the hydraulic properties of the two soil types were taken from Macinnis-Ng et al. [40] and Carsel and Parrish [44] (Table 1). We set the pressure head at the bottom boundary to be constant and equal to $-6.09 \mathrm{~m}$, corresponding to a volumetric water content of 0.28 . This is consistent with discrete soil moisture observations reported by Yunusa et al. [42], which showed that the water content in the clay layer at a depth of $5 \mathrm{~m}$ exhibited small fluctuations around this value. The measured rainfall rate was used as a flux boundary condition at the surface. As an initial condition, we assumed the pressure head in the sand layer to be constant and equal to $-0.402 \mathrm{~m}$, corresponding to a volumetric moisture content of 0.08 ; this is in agreement with estimates from soil moisture measurements. In the clay layer, we assumed that the pressure head below an elevation of $3 \mathrm{~m}$ was constant and equal to -6.09 $\mathrm{m}$; this is in agreement with the soil moisture measurements reported by Yunusa et al. [42]. Between elevations 3 and $4.2 \mathrm{~m}$, the pressure head was interpolated linearly from -6.09 to $-0.402 \mathrm{~m}$.

The plant domain consists of above and below-ground xylem. In the soil-plant-atmosphere model presented by Zeppel et al. [12] and applied to the same site, the Authors used a maximum root depth of $3.2 \mathrm{~m}$, stressing that, although measurements showed that most of the roots were in the top $1.5 \mathrm{~m}$, the model was not able to simulate the sustained transpiration rates unless a depth of at least $3 \mathrm{~m}$ was assumed. In accordance with Zeppel 
et al. [12], we also used a root depth of $3.2 \mathrm{~m}$. The boundary conditions for the plant domain are a zero-flux condition at the bottom of the roots and, above ground, transpiration rates define the flux at the top of the canopy. We used the Penman-Monteith equation coupled to the Jarvis formulation for canopy stomatal conductance to simulate transpiration. Since positive sap flux was often measured during the night, and according to the Jarvis formulation stomatal conductance is zero in the absence of solar radiation, we included nocturnal transpiration using an empirical function based on the measurements reported by Zeppel et al. [39] (see details in Appendix B). As an initial condition, we assume that the xylem pressure head decreased linearly from $-6.09 \mathrm{~m}$ at the bottom of the roots to $-23.3 \mathrm{~m}$ at the top of the canopy.

The list of xylem parameters are presented in Table 2. The values of most of the parameters were taken from either measurements at the site or from the literature. The parameters $\theta_{2}$ and $n_{l}$ were estimated within the range of values found in the literature; $T_{o p t}$ was estimated to be about the annual average daily temperature at the site, i.e., $16^{\circ} \mathrm{C}$. The parameter $k_{d}$ was estimated at $1.1 \cdot 10^{-3} \mathrm{~Pa}^{-1}$, similar to the value used in Daly et al. [46] (i.e., $0.8 \cdot 10^{-3} \mathrm{~Pa}^{-1}$ ). The value of $g_{\max }$ was assumed to be $10 \mathrm{~mm} \mathrm{~s}^{-1}$ (about 410 mmol $\left.\mathrm{m}^{-2} \mathrm{~s}^{-1}\right)$, consistent with the maximum stomatal conductance observed at the site [48]. The parameters $k_{s r t}, S_{s}$, and $h_{x 50}$ were randomly varied, within an interval of reasonable values, until a combination of parameters producing a satisfactory fit between observations and model predictions was achieved. 

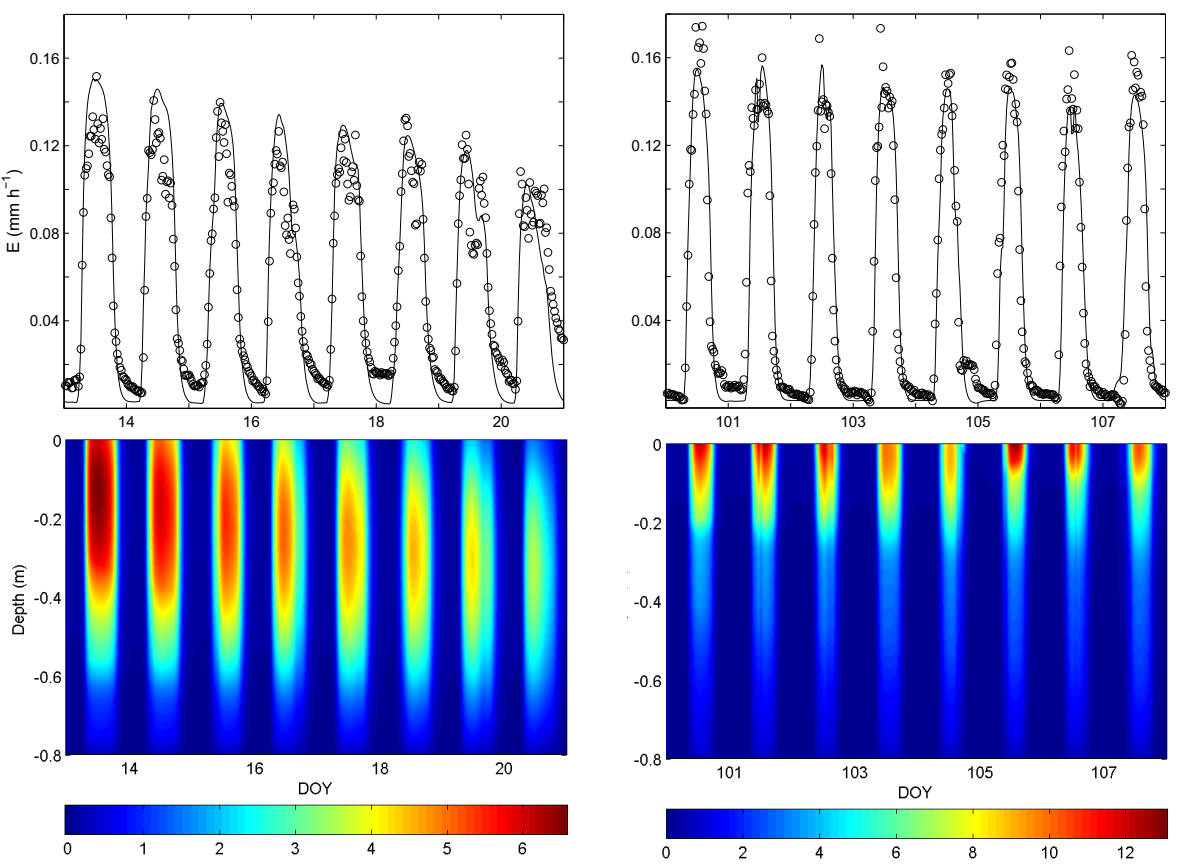

Figure 3: Top: Comparison between measured (circles) and modeled (lines) sap flux rates at $1.3 \mathrm{~m}$ above ground for two different time periods. Bottom: corresponding root water uptake rates, $S\left[10^{3} \mathrm{~d}^{-1}\right]$, profiles in the top $0.8 \mathrm{~m}$ from the surface. The total root depth is $3.2 \mathrm{~m}$.
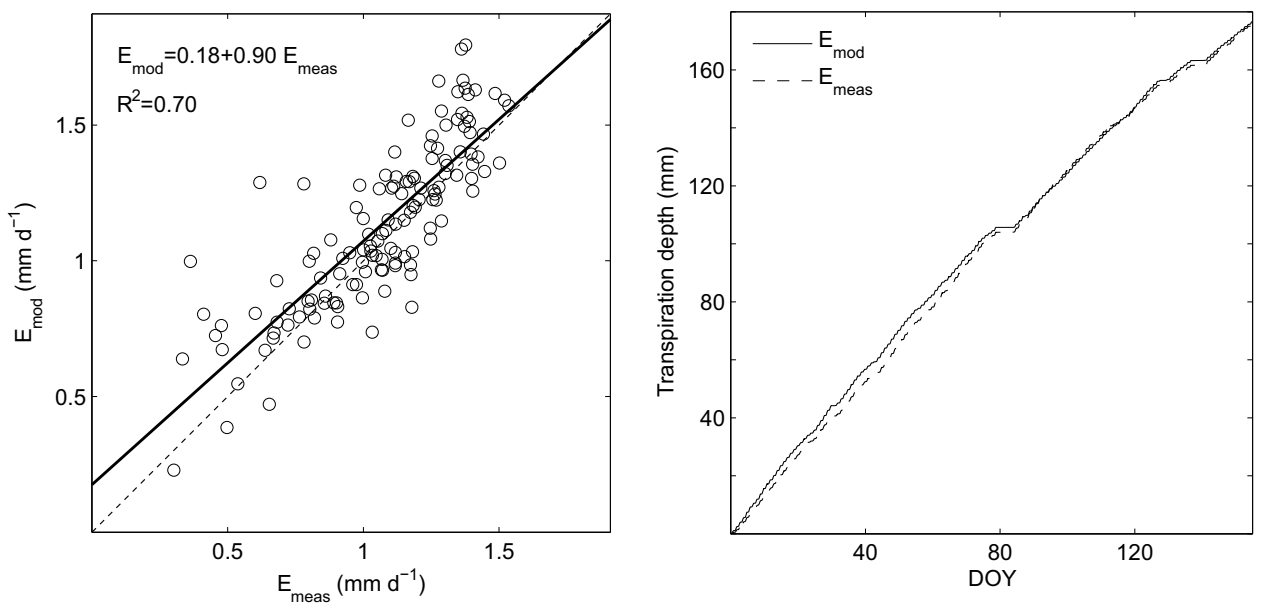

Figure 4: Left: Comparison between measured $\left(E_{\text {meas }}\right)$ and modeled $\left(E_{\text {mod }}\right)$ daily sap flux rates at $1.3 \mathrm{~m}$ above ground, excluding fluxes during nights. Right: cumulative plot of measured (dashed line) and modeled (continuous line) sap fluxes. 


\subsection{Results}

Measured transpiration rates shown in Figure 1 present daily cycles with very similar magnitudes across several months, not-with-standing the reductions in solar radiation, temperature and vapor pressure deficit as well as variability of rainfall across the study period. The model was able to capture these sustained transpiration rates.

The Nash-Sutcliffe Efficiency (NSE) coefficient for the whole series of data was 0.86 , indicating an acceptable agreement between modeled and measured sap flux. Since modeling transpiration during the night was not the focus of this work, we removed the data corresponding to nights; the NSE in this case remained high, but was reduced to 0.71 . Figure 3 shows the comparison between daily patterns of measured and modeled sap flux at $1.3 \mathrm{~m}$ above ground. Two periods of the year are shown: a dry period in summer, between days 13 and 20, and a wetter period in autumn, between days 100 and 107 . The patterns of root water uptake generating these transpiration rates are also shown in Figure 3. In the driest part of the simulated period, between days 13 and 20, when soil near the surface becomes very dry, roots were able to compensate for this lack of soil water content by increasing water uptake from deeper soil layers. Root water compensation was also present, although not so clearly evident, during wetter periods. In these periods, the majority of water for transpiration was provided by soil near the surface, where most of the roots are, but part of the transpired water was always supported by deeper soil layers.

Rates of daily sap flux, excluding nights, were also satisfactorily reproduced by the model (Figure 4), with NSE equal to 0.58. The coefficient of 

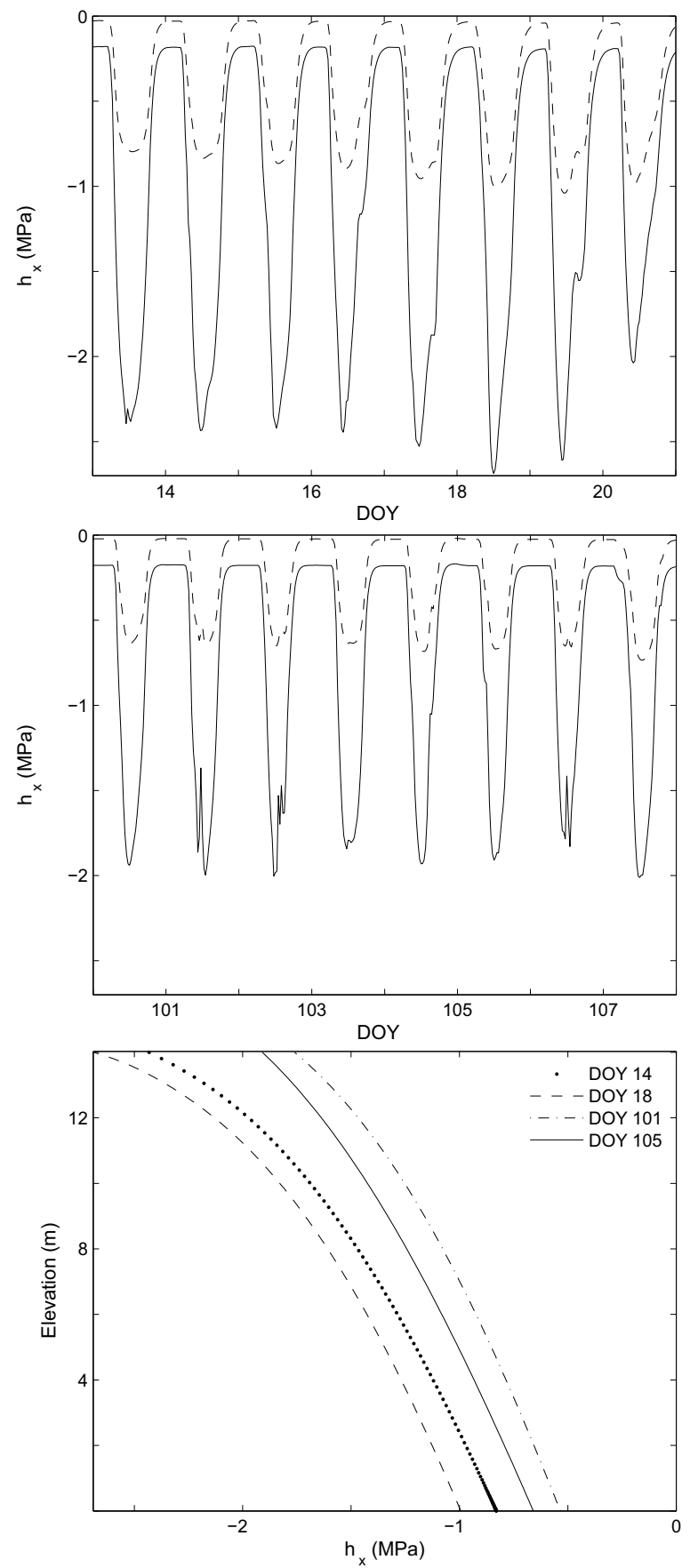

Figure 5: Modeled leaf water potential (continuous line) and root water potential at the surface (dashed line) in two different periods. The panel at the bottom shows the xylem potential as a function of height above ground at $12 \mathrm{pm}$ in four different days. 
determination between modeled and observed data was 0.70 , with the slope of the least-squares regression line being 0.90 (with $95 \%$ confidence interval ranging from 0.80 to 1.00) with an intercept of 0.17 (with $95 \%$ confidence interval between 0.06 and 0.29 ). Figure 4 also shows the cumulative amount of water transpired by the vegetation and that obtained from the model during the simulated period.

Examples of modeled water potentials in the xylem are shown in Figure 5. The modeled leaf water potential oscillated around $-0.2 \mathrm{MPa}$ at pre-dawn and reached values of about $-3 \mathrm{MPa}$ in the middle of the day. These values are consistent with the leaf water potentials measured by Zeppel et al. [12] on four days during the period September-December; measured pre-dawn values for E. parramattensis and A. bakeri were between -0.18 and $-1.77 \mathrm{MPa}$, while minimum leaf water potentials were between -1.81 and $-3.60 \mathrm{MPa}$. In the same study, Zeppel et al. [12] used in their soil-plant-atmosphere model a value of $-2.8 \mathrm{MPa}$ as a minimum sustainable leaf water potential, which is consistent with the values obtained in our model. The modelled difference between root and leaf water potentials during the night were due to both differences in elevations ( $14 \mathrm{~m}=0.14 \mathrm{MPa}$ between soil surface and leaves) and transpiration during the night. The gradient in water potentials between roots and leaves were sufficient to generate a flux of water from the soil to the atmosphere, such that the model did not show fluxes of water from roots to the soil possibly associated with hydraulic redistribution. Figure 5 also shows variation of above-ground xylem water potential for different days at $12 \mathrm{pm}$. The decrease of the xylem water potential with height is non-linear because of the reduction in xylem conductivity (Eq. 7) caused by low leaf 
water potentials.

\section{Root water uptake with different root depths}

Previous studies and the sap flux data in Figure 1 show that trees at the site are able to maintain sustained daily sap-flux rates across several months; the reason for this has been attributed to the continuous presence of water near the interface between the sand and clay layers, which acts as a buffer during dry periods [12]. Thus, when the sand becomes dry near the surface, the trees are able to increase their water uptake from deeper soil layers, even though a lower percentage of roots are present at these depths. Since data on root density were available only to a depth of $1.5 \mathrm{~m}$, we modeled the root water uptake when root depths lower than $3.2 \mathrm{~m}$ are assumed. We recall that in the model used by Zeppel et al. [12], which did not account for root water compensation, a minimum root depth of $3 \mathrm{~m}$ was required to satisfactorily describe the observed sap flow rates. Eucalyptus species are generally evergreen and require deep root systems; other species (e.g., drought deciduous species) might require shallower root depths. We now consider root depths decreasing from a maximum of $d=3.2 \mathrm{~m}$ to a minimum of $d=0.9 \mathrm{~m}$, to establish whether different root depths in our model are able to maintain the observed sap fluxes. We thus assumed that the root distribution had the shape as in Eq. (3), modifying only the value of $d$; since we used Eq. (2), this assumption implies that the root mass remained the same in all simulations, but it was distributed differently along the root depth.

According to the model results, the water transpired over the period under analysis decreased with shallower root depths (Figure 6). Similar transpira- 

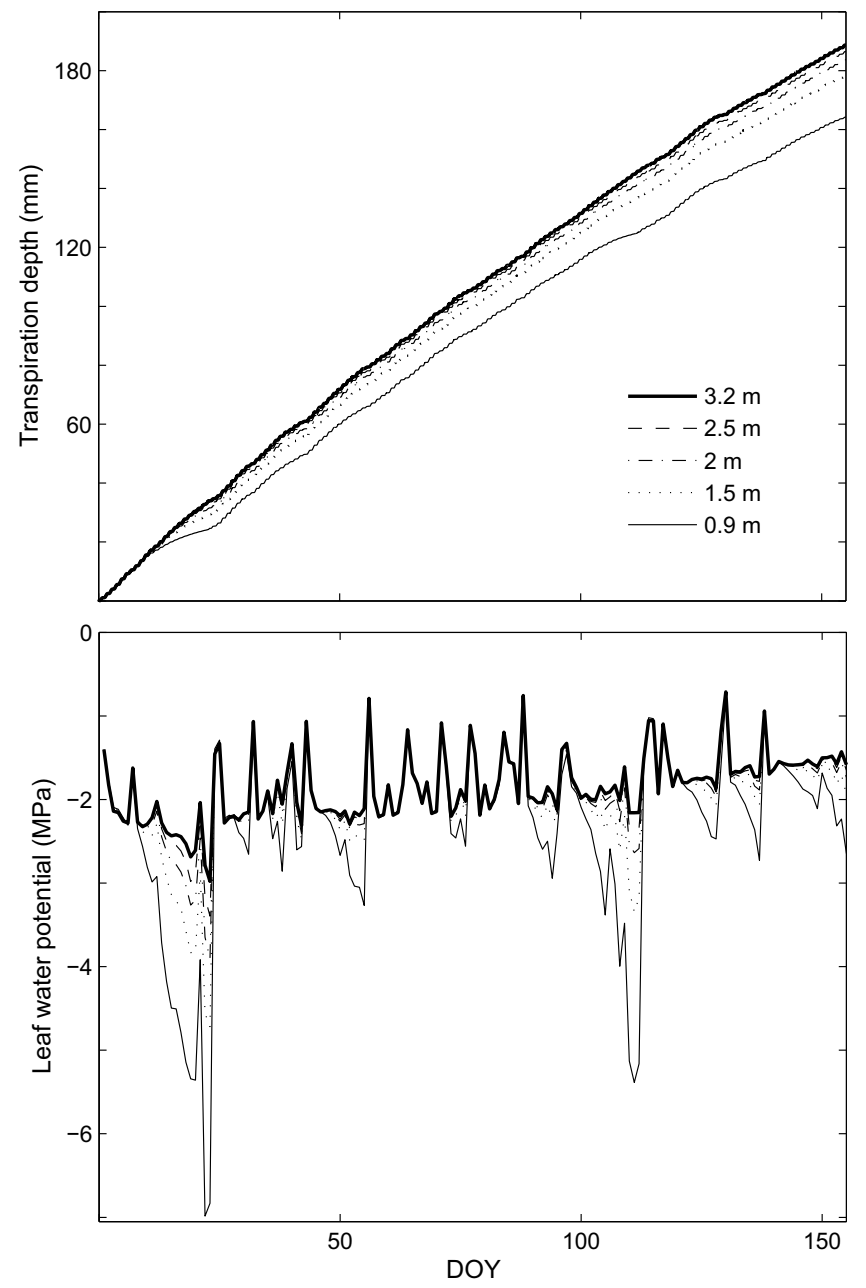

Figure 6: Modeled cumulative transpiration rates (top) and daily minimum leaf water potentials (bottom) obtained with root depths decreasing from 3.2 to $0.9 \mathrm{~m}$. 
tion rates were obtained with root depths from 3.2 to $2 \mathrm{~m}$, while transpiration declined more noticeably with depths lower than about $2 \mathrm{~m}$. Specifically, when assuming that the roots were almost entirely in the sandy layer (i.e., $d=0.9 \mathrm{~m}$ ), the total transpiration after 155 days was about $24 \mathrm{~mm}$ lower than in the case with $d=3.2 \mathrm{~m}$. In order to maintain such high transpiration rates even with shallower root depths, the vegetation needs to lower the xylem water potential. As shown in Figure 6, the minimum leaf water potential that the trees needed to sustain became much lower as root depth decreased. The values of leaf water potential obtained with root depths lower than about $2 \mathrm{~m}$ were very low and unrealistic when compared to measurements at the site [12]. For all root depths, the daily minimum leaf water potential was below $h_{x 50}$ for $91 \%$ of the days. With $d=3.2 \mathrm{~m}$, the daily averaged leaf water potential stayed above $h_{x 50}$ during the entire period simulated; as $d$ decreased, the percentage of days in which the daily averaged leaf water potential went below $h_{x 50}$ increased from $1.3 \%$, for $d=2.5 \mathrm{~m}$, to $11 \%$, when $d$ was $0.9 \mathrm{~m}$.

The reduction in transpiration with shallower root depths is evident by comparing the results in Figure (7) with those in Figure (3). With shallower root depths, the vegetation was more reliant on soil moisture near the surface. Larger water uptake rates near the surface after rainfall events caused a quick drying of the sandy layer. With water uptake occurring mostly from the sand layer and the high hydraulic conductivity of the sand, soil moisture content declined near the surface inducing water stress in the vegetation. Root water compensation was still evident during dry periods, but the lower moisture available reduced the water uptake in comparison to the case with deeper 

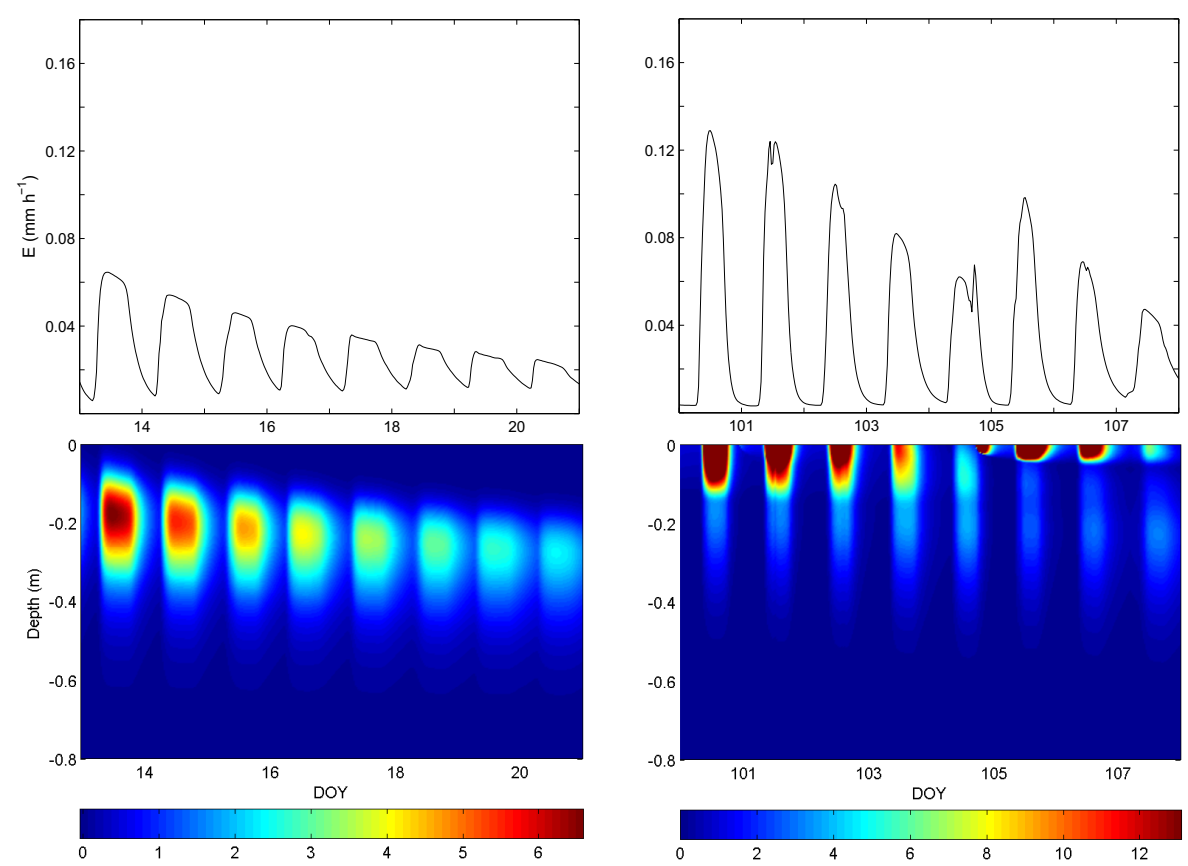

Figure 7: Top: Modeled sap flux rates at $1.3 \mathrm{~m}$ from the ground for two different time periods using a total root depth of $0.9 \mathrm{~m}$. Bottom: corresponding root water uptake rates, $S\left[10^{3} \mathrm{~d}^{-1}\right]$, profiles in the top $0.8 \mathrm{~m}$ from the surface. 
root depths. Even in wetter periods, the shallow rooted vegetation is more dependent on rainfall. This is for example shown by the rapid water uptake near the surface occurring towards the end of the day 104, when $1 \mathrm{~mm}$ of water fell in 30 minutes (Figure 7). This small event did not cause any significant change in the root water uptake when the root depth was set to $3.2 \mathrm{~m}$ (Figure 3).

Most of the root water uptake occurred within the first $0.8 \mathrm{~m}$ of soil. Figure (8) shows how daily root water uptake is partitioned among various parts of the root system comparing different root depths. With $d=3.2 \mathrm{~m}$, about $15 \%$ of the daily root water uptake consistently came from soil layers deeper than $0.6 \mathrm{~m}$, where about $15 \%$ of the roots are; during dry periods, the percentage of water from these depths increased, reaching about $30 \%$ in the driest part of the period analyzed. When reducing the root depth, the roots between 0.3 and $0.6 \mathrm{~m}$ became more important during dry periods. They contributed at times more than $50 \%$ of the total daily rott water uptake, even though less than $20 \%$ of the roots were at these depths.

To see the effect of lower rainfall rates on the partitioning of root water uptake, we ran the same simulations using as input $70 \%$ of the rainfall rates measured at the site (i.e., a total rainfall of $350 \mathrm{~mm}$ ). The total transpiration rates in this case were slightly lower than those obtained before, and these transpiration rates were achieved thanks to lower leaf water potentials (not shown). The partition of root water uptake from different depths did not differ considerable from what shown in Figure (8). 

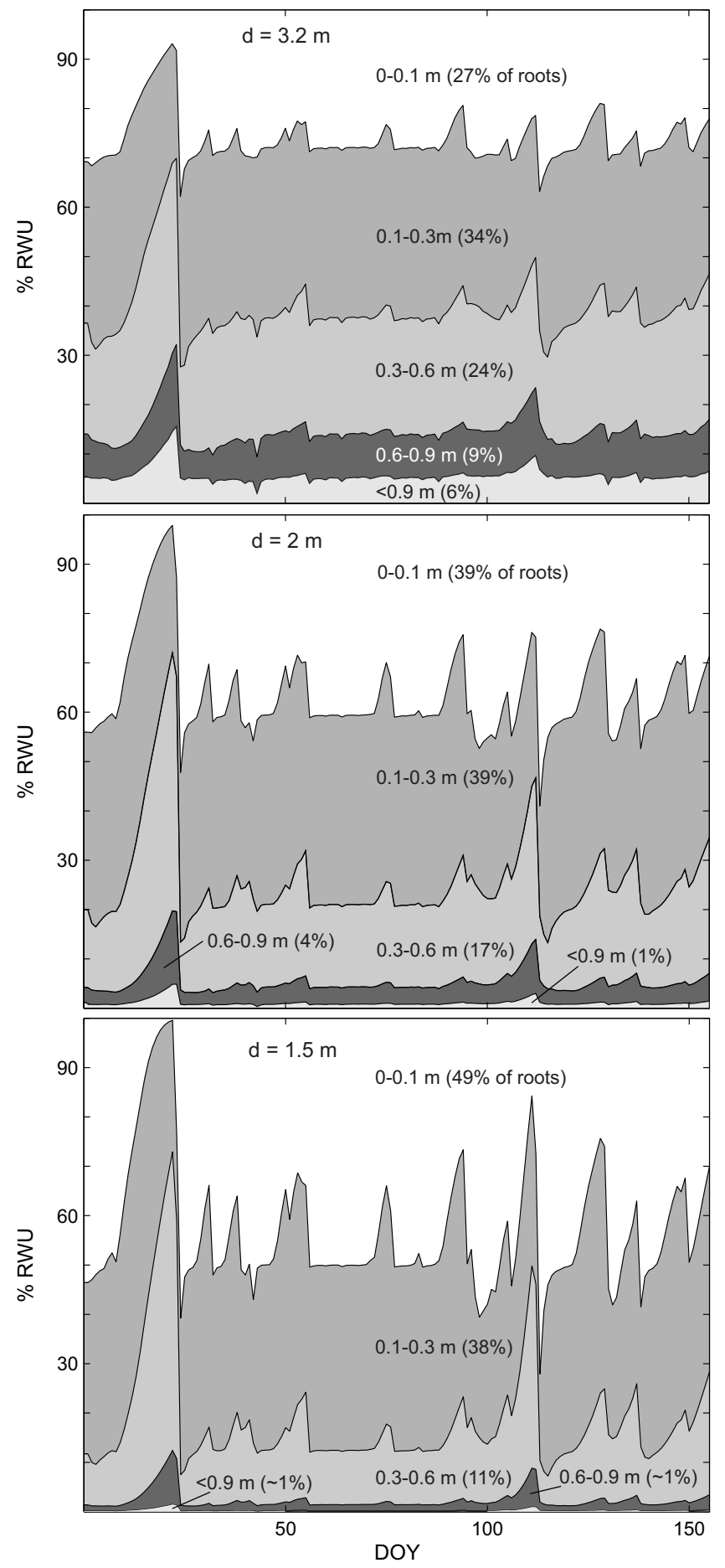

Figure 8: Percentage of daily total root water uptake (RWU) from various parts of the root system for three different root depths, $\underset{23}{d}$ 


\section{Conclusions}

Root water compensation is the mechanism through which vegetation adjusts the depth of root water uptake based on soil water availability, thereby favoring uptake from areas of the soil that have higher water potentials even when the root density is relatively low in these areas. We present here a modeling study that helps show the key role of root water compensation in maintaining sustained transpiration rates in an Australian woodland growing on a duplex soil.

Using a one dimensional model that couples water flow in the soil to that in the xylem, we were able to reproduce field observations of transpiration rates over a period of several months. The root depth in this simulation was initially assumed to be $3.2 \mathrm{~m}$; this value was adopted in a previous study at the same site [12]. Root water uptake from the model suggested that root water compensation was a key mechanism that allowed trees to maintain stable transpiration rates during dry periods of the year; root water compensation was also present during relatively wet periods. The roots below a depth of $0.6 \mathrm{~m}$, totaling to about $15 \%$ of the whole root biomass, provided consistently nearly $15 \%$ of the daily transpiration, reaching $30 \%$ in the driest part of the analyzed period.

The roots below a depth of $0.6 \mathrm{~m}$, totaling to about $15 \%$ of the whole root biomass, provided between $15 \%$ and $30 \%$ of the daily transpiration.

Scenarios with different root depths, from 3.2 to $0.9 \mathrm{~m}$, showed that in all cases root water compensation was actively involved in sustaining transpiration rates, which anyway reduced considerably for root depths shallower than about $2 \mathrm{~m}$. For such depths, transpiration rates were sustained by decreasing 
leaf water potentials, which were much lower than what was experimentally observed. The model suggested that the vegetation with shallower root system is more responsive to rainfall events; in this case the soil surface becomes drier and vegetation is more prone to experience water stress, thereby reducing transpiration rates. Root depths shallower than $2 \mathrm{~m}$, with a percentage of root biomass below $0.6 \mathrm{~m}$ of less than about $5 \%$, reduced transpiration rates because of water stress and led to leaf water potentials much lower than field observations. In those scenarios, roots deeper than $0.3 \mathrm{~m}$ provided up to $70 \%$ of the daily transpiration even though root biomass at these depths was less than $15 \%$.

Our results can likely be extended to other areas with duplex soils and shallow water table conditions, where large amounts of water can be reached by the roots. In such conditions, roots can switch their preferential water uptake from near the surface immediately after rainfall events to deeper soil layers, where the wet soil allows for larger differences between soil and root water potentials. Our study thus shows that duplex soils might provide energetically favorable conditions for root water uptake near the interface between the layers, thereby allowing vegetation to maintain sustained transpiration rates not-with-standing intermittent wet and dry periods.

\section{Appendix A. Water retention curves}

In unsaturated conditions, the soil moisture $(\theta)$ and unsaturated hydraulic conductivity $(k)$ vary with soil pressure head $\left(h_{s}\right)$. The relationship between these variables are modeled as [36]: 


$$
\begin{gathered}
\theta= \begin{cases}\theta_{r}+\frac{\theta_{s}-\theta_{r}}{\left[1+\left|\alpha h_{s}\right|^{n}\right]^{m}} & \text { if } h_{s}<0, \\
\theta_{s} & \text { if } h_{s} \geq 0,\end{cases} \\
k= \begin{cases}k_{s}\left(\frac{\theta-\theta_{r}}{\theta_{s}-\theta_{r}}\right)^{l}\left[1-\left(1-\left(\frac{\theta-\theta_{r}}{\theta_{s}-\theta_{r}}\right)^{1 / m}\right)^{m}\right]^{2} & \text { if } h_{s}<0, \\
k_{s} & \text { if } h_{s} \geq 0,\end{cases}
\end{gathered}
$$

where $\theta_{r}\left[L^{3} L^{-3}\right]$ is the residual water content, $\theta_{s}\left[L^{3} L^{-3}\right]$ is the water content at saturation, $k_{s}\left[L T^{-1}\right]$ is the soil hydraulic conductivity at saturation and $\alpha\left[L^{-1}\right], l[-], n[-]$ are parameters dependent on soil type; the parameter $m[-]$ is equal to $1-1 / n$.

\section{Appendix B. Penman-Monteith equation}

The Penman-Monteith equation reads:

$$
E_{p}=\left[\frac{Q_{n} \Delta+C_{p} D g_{a}}{\lambda\left[\Delta g_{c}+\gamma\left(g_{c}+g_{a}\right)\right]}\right] g_{c}
$$

where $E_{p}\left[L T^{-1}\right]$ is the transpiration rate, $Q_{n}\left[M T^{-3}\right]$ is the net radiation, $\Delta\left[M L^{-1} T^{-2} K^{-1}\right]$ is the slope of the saturation vapor pressure curve at a given air temperature, $C_{p}\left[M L^{-1} T^{-2} K^{-1}\right]$ is the heat capacity of air at constant pressure, $D\left[M L^{-1} T^{-2}\right]$ is the vapour pressure deficit, $\lambda\left[M L^{-1} T^{-2}\right]$ is 
the latent heat of vaporization, $g_{a}\left[L T^{-1}\right]$ is the aerodynamic conductance, $\gamma\left[M L^{-1} T^{-2} K^{-1}\right]$ is the psychrometric constant and $g_{c}\left[L T^{-1}\right]$ is the canopy conductance. The net radiation is calculated as the $70 \%$ of the total radiation, $S$ [49]. The slope of the saturation vapor pressure curve, $\Delta$, is obtained as [50]:

$$
\Delta=\left[\frac{4098}{\left(T_{a}-35.85\right)^{2}}\right] e_{s a t}
$$

where $e_{\text {sat }}\left[M L^{-1} T^{-2}\right]$ is the saturation vapor pressure at a given air temperature $T_{a}[K]$, and given by the equation [50]:

$$
e_{\text {sat }}=611 \exp \left[\frac{17.27\left(T_{a}-273.15\right)}{\left(T_{a}-35.85\right)}\right]
$$

with $e_{\text {sat }}$ in Pascal.

The canopy conductance, $g_{c}$, was modeled as:

$$
g_{c}=\left[\frac{g_{s} g_{b}}{g_{s}+g_{b}}\right] L A I,
$$

where $L A I[-]$ is the leaf area index, $g_{b}\left[L T^{-1}\right]$ is the leaf boundary layer conductance per unit leaf area and $g_{s}\left[L T^{-1}\right]$ is the stomatal conductance. Assuming that $\mathrm{CO}_{2}$ concentrations remain constant and do not affect the stomatal conductance, $g_{s}$ can be modeled as [51]:

$$
g_{s}=g_{\text {smax }} f(S) f\left(T_{a}\right) f(D) f\left(h_{\text {xleaf }}\right),
$$


where $g_{\text {smax }}\left[L T^{-1}\right]$ is the maximum stomatal conductance per unit leaf area, and $f(S)[-], f\left(T_{a}\right)[-], f(D)[-]$, and $f\left(h_{\text {xleaf }}\right)[-]$ are empirical functions varying between 0 and 1 , which scale $g_{\text {smax }}$ depending on solar radiation, air temperature, vapor pressure deficit and leaf water potential. These functions are commonly written as:

$$
\begin{gathered}
f(S)=1-\exp \left(-k_{r} S\right), \\
f\left(T_{a}\right)=1-k_{t}\left(T_{a}-T_{\text {opt }}\right)^{2}, \\
f(D)=\frac{1}{\left(1+D k_{d}\right)}, \\
f\left(h_{\text {xleaf }}\right)=\left[1+\left(\frac{h_{\text {xleaf }}}{h_{x 50}}\right)^{n_{l}}\right]^{-1},
\end{gathered}
$$

where $k_{r}, k_{t}, k_{d}$ and $n_{l}$ are empirical constants, $T_{o p t}$ is the air temperature at which $f(T)$ is 1 , and $h_{x 50}$ is the leaf water potential at which $f\left(h_{x l e a f}\right)$ is 0.5 .

We model the night time transpiration as:

$$
E_{n}=E_{\text {max }} f\left(T_{a}\right) f(D) f\left(h_{x l e a f}\right),
$$

where $E_{\max }\left[L T^{-1}\right]$ is the maximum night time transpiration assumed to be equal to $1 \cdot 10^{-9} \mathrm{~m} \mathrm{~s}^{-1}$ based on the observed night time sap flux. 


\section{Appendix C. Water flow in above ground xylem}

Above ground, for a single plant, the water flow through the xylem can be written as $[52,53]$ :

$$
\begin{aligned}
& \rho g S_{s}\left(\frac{\partial h_{x}}{\partial t}\right)-\frac{1}{A(z)} \frac{\partial}{\partial z}\left[k_{p}\left(h_{x}, z\right) A(z)\left(\frac{\partial h_{x}}{\partial z}+1\right)\right]= \\
& -\frac{1}{A(z)} \tau(z) E_{d}\left(z, t, h_{x}\right)
\end{aligned}
$$

where $A(z)\left[L^{2}\right]$ is the cross-sectional area of the above ground xylem, $k_{p}\left[L T^{-1}\right]$ is the xylem conductivity per unit of xylem cross-sectional area, $\tau(z)[L]$ is the leaf area per unit of stem length, and $E_{d}\left(z, t, h_{x}\right)\left[L T^{-1}\right]$ is the transpiration flux density. For simplicity, we assume a uniform xylem cross sectional area above ground, and thus $A(z)$ becomes a constant. Therefore, $A(z)$ on the 1.h.s. of Eq. (C.1) at the numerator and denominator cancel each other. Since we do not consider a canopy structure, the term on the r.h.s of Eq. (C.1) becomes zero.

Because Eqs. (1) and (5) define transpiration per unit of ground area, we need to re-scale Eq. (C.1) from the xylem cross-sectional area of a single plant to the unit of ground area. This is obtained by re-scaling the axial hydraulic conductivity, $k_{p}$, which is multiplied by the ratio $A_{x} / A_{s}$, where $A_{x}$ is the average xylem cross-sectional area of all the plants in the ground area $A_{s}$. Accordingly, Eq. (C.1) becomes Eq. (6). 


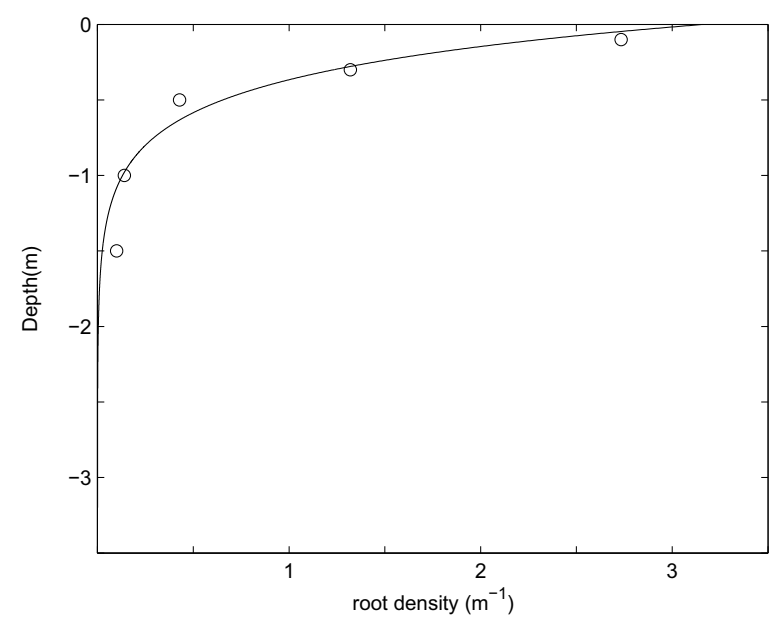

Figure D.9: Modeled root distribution with $d=3.2 \mathrm{~m}$ (continuous line) and measured distribution (circles) [40].

\section{Appendix D. Estimated root distribution}

The root distribution when the root depth equals $3.2 \mathrm{~m}$ was estimated from the data presented in Figure 4 of Macinnis-Ng et al. [40]. The percentage of roots at $0.1,0.3,0.5,1.0$, and $1.5 \mathrm{~m}$ was measured in four trenches. We averaged the results from the four trenches and assumed that the percentage of roots at $0.1 \mathrm{~m}$ was distributed over the first $0.15 \mathrm{~m}$ of soil; the value at 0.3 $\mathrm{m}$ referred to the soil between 0.15 and $0.40 \mathrm{~m}$, the value at $0.5 \mathrm{~m}$ referred to the soil between 0.40 and $0.75 \mathrm{~m}$, the value at $1.0 \mathrm{~m}$ referred to the soil between 0.75 and $1.25 \mathrm{~m}$, and the value at $1.5 \mathrm{~m}$ referred to the depths between 1.25 and $1.75 \mathrm{~m}$. Dividing the values of the averaged percentage of roots by the respective depth interval gives and estimation of the root density.

The parameter $q_{z}$ of the root distribution (Eq. 2) with $d=3.2 \mathrm{~m}$ was chosen to fit the root estimated from these calculation, as shown in Figure 
D.9.

\section{Acknowledgements}

The authors thank Melanie J. B. Zeppel for providing the data used in the study. P.V., D.E. and E.D. acknowledge the support of the Australian Research Council (ARC) and the Australian National Water Commission (NWC) through Program 4 (Groundwater Vegetation Atmosphere Interactions) of the National Centre for Groundwater Research and Training. P.V. thanks the Director of the National Environmental Engineering Research Institute, Nagpur, India, for granting leave to pursue his $\mathrm{PhD}$ studies at Monash University.

\section{References}

[1] G. Bonan, Ecological Climatology: Concepts and Applications, Cambridge University Press, Cambridge, UK, 2002.

[2] L. M. Arya, G. R. Blake, D. A. Farrell, Field study of soil-water depletion patterns in presence of growing soybean roots. 3. Rooting characteristics and root extraction of soil-water, Soil Science Society of America Journal 39 (3) (1975) 437-444.

[3] J. U. Nnyamah, T. A. Black, Rates and patterns of water-uptake in a Douglas-fir forest, Soil Science Society of America Journal 41 (5) (1977) 972-979.

[4] S. R. Green, B. E. Clothier, Root water uptake by kiwifruit vines following partial wetting of the root zone, Plant and Soil 173 (2) (1995) $317-328$. 
[5] E. H. McLean, M. Ludwig, P. F. Grierson, Root hydraulic conductance and aquaporin abundance respond rapidly to partial root-zone drying events in a riparian Melaleuca species, New Phytologist 192 (3) (2011) 664-675, doi:10.1111/j.1469-8137.2011.03834.x.

[6] M. M. Caldwell, T. E. Dawson, J. H. Richards, Hydraulic lift: Consequences of water efflux from the roots of plants, Oecologia 113 (2) (1998) $151-161$.

[7] R. J. Ryel, M. M. Caldwell, C. K. Yoder, D. Or, A. J. Leffler, Hydraulic redistribution in a stand of Artemisia tridentata: evaluation of benefits to transpiration assessed with a simulation model, Oecologia 130 (2) (2002) 173-184, doi:10.1007/s004420100794.

[8] I. Prieto, Z. Kikvidze, F. I. Pugnaire, Hydraulic lift: Soil processes and transpiration in the Mediterranean leguminous shrub Retama sphaerocarpa (L.) Boiss, Plant and Soil 329 (1) (2010) 447-456.

[9] L. H. Li, Y. P. Wang, Q. Yu, B. Pak, D. Eamus, J. H. Yan, E. van Gorsel, I. T. Baker, Improving the responses of the Australian community land surface model (CABLE) to seasonal drought, Journal of Geophysical Research-Biogeosciences 117, doi:10.1029/2012jg002038.

[10] A. J. Guswa, Canopy vs. roots: Production and destruction of variability in soil moisture and hydrologic fluxes, Vadose Zone Journal 11 (3).

[11] F. Orellana, P. Verma, S. P. I. Loheide, E. Daly, Monitoring and Modeling Water-Vegetation Interaction in Groundwater-Dependent Ecosystems, Reviews of Geophysics 50 (RG3003) (2012) 1-24. 
[12] M. Zeppel, C. MacInnis-Ng, A. Palmer, D. Taylor, R. Whitley, S. Fuentes, I. Yunusa, M. Williams, D. Eamus, An analysis of the sensitivity of sap flux to soil and plant variables assessed for an Australian woodland using a soil-plant-atmosphere model, Functional Plant Biology 35 (6) (2008) 509-520.

[13] N. J. Jarvis, A simple empirical model of root water-uptake, Journal of Hydrology 107 (1-4) (1989) 57-72, doi:10.1016/0022-1694(89)90050-4.

[14] M. Javaux, V. Couvreur, J. Vander Borght, H. Vereecken, Root Water Uptake: From Three-Dimensional Biophysical Processes to Macroscopic Modeling Approaches, Vadose Zone Journal 12 (4), doi: 10.2136/vzj2013.02.0042.

[15] N. J. Jarvis, Simple physics-based models of compensatory plant water uptake: concepts and eco-hydrological consequences, Hydrology and Earth System Sciences 15 (11) (2011) 3431-3446, doi:10.5194/hess-15$3431-2011$.

[16] J. A. Vrugt, M. T. Van Wijk, J. W. Hopmans, J. imunek, One-, two-, and three-dimensional root water uptake functions for transient modeling, Water Resources Research 37 (10) (2001) 2457-2470.

[17] J. A. Vrugt, J. W. Hopmans, J. Simunek, Calibration of a TwoDimensional Root Water Uptake Model, Soil Sci. Soc. Am. J. 65 (4) (2001) 1027-1037, doi:10.2136/sssaj2001.6541027x.

[18] T. Skaggs, M. van Genuchten, P. Shouse, J. Poss, Macroscopic ap- 
proaches to root water uptake as a function of water and salinity stress, Agricultural Water Management 86 (1-2) (2006) 140-149.

[19] K. Y. Li, R. De Jong, J. B. Boisvert, An exponential root-water-uptake model with water stress compensation, Journal of Hydrology 252 (1-4) (2001) 189-204.

[20] B. K. Yadav, S. Mathur, M. A. Siebel, Soil moisture dynamics modeling considering the root compensation mechanism for water uptake by plants, Journal of Hydrologic Engineering 14 (9) (2009) 913-922.

[21] J. Simunek, J. W. Hopmans, Modeling compensated root water and nutrient uptake, Ecological Modelling 220 (4) (2009) 505-521, doi: 10.1016/j.ecolmodel.2008.11.004.

[22] M. Siqueira, G. Katul, A. Porporato, Onset of water stress, hysteresis in plant conductance, and hydraulic lift: Scaling soil water dynamics from millimeters to meters, Water Resources Research 44 (W01432) (2008) 1-14, doi:W01432 10.1029/2007wr006094.

[23] M. Siqueira, G. Katul, A. Porporato, Soil Moisture Feedbacks on Convection Triggers: The Role of Soil-Plant Hydrodynamics, Journal of Hydrometeorology 10 (1) (2009) 96-112, doi:10.1175/2008jhm1027.1.

[24] S. Tron, F. Laio, L. Ridolfi, Plant water uptake strategies to cope with stochastic rainfall, Advances in Water Resources 53 (2013) 118-130, doi: 10.1016/j.advwatres.2012.10.007.

[25] T. Vogel, M. Dohnal, J. Dusek, J. Votrubova, M. Tesar, Macroscopic 
Modeling of Plant Water Uptake in a Forest Stand Involving RootMediated Soil Water Redistribution, Vadose Zone Journal 12 (1), doi: 10.2136/vzj2012.0154.

[26] M. Mendel, S. Hergarten, H. J. Neugebauer, On a better understanding of hydraulic lift: A numerical study, Water Resources Research 38 (10) (2002) 11-110.

[27] G. G. Amenu, P. Kumar, A model for hydraulic redistribution incorporating coupled soil-root moisture transport, Hydrology and Earth System Sciences 12 (1) (2008) 55-74.

[28] J. C. Quijano, P. Kumar, D. T. Drewry, A. Goldstein, L. Misson, Competitive and mutualistic dependencies in multispecies vegetation dynamics enabled by hydraulic redistribution, Water Resources Research 48 (W05518) (2012) 1-22, doi:W05518 10.1029/2011wr011416.

[29] S. Gou, G. Miller, A groundwatersoilplantatmosphere continuum approach for modelling water stress, uptake, and hydraulic redistribution in phreatophytic vegetation, Ecohydrology 7 (3) (2013) 1029-1041, doi: 10.1002/eco.1427.

[30] Q. D. van Lier, J. C. van Dam, K. Metselaar, R. de Jong, W. H. M. Duijnisveld, Macroscopic root water uptake distribution using a matric flux potential approach, Vadose Zone Journal 7 (3) (2008) 1065-1078, doi:10.2136/vzj2007.0083.

[31] N. J. Jarvis, Comment on "Macroscopic Root Water Uptake Distribu- 
tion Using a Matric Flux Potential Approach", Vadose Zone Journal 9 (2) (2010) 499-502, doi:10.2136/vzj2009.0148.

[32] C. Doussan, A. Pierret, E. Garrigues, L. Pages, Water uptake by plant roots: II - Modelling of water transfer in the soil root-system with explicit account of flow within the root system - Comparison with experiments, Plant and Soil 283 (1-2) (2006) 99-117, doi:10.1007/s11104-0047904-z.

[33] G. Bohrer, H. Mourad, T. A. Laursen, D. Drewry, R. Avissar, D. Poggi, R. Oren, G. G. Katul, Finite element tree crown hydrodynamics model (FETCH) using porous media flow within branching elements: A new representation of tree hydrodynamics, Water Resources Research 41 (W11404) (2005) 1-17, doi:10.1029/2005wr004181.

[34] M. Janott, S. Gayler, A. Gessler, M. Javaux, C. Klier, E. Priesack, A one-dimensional model of water flow in soil-plant systems based on plant architecture, Plant and Soil 341 (1-2) (2011) 233-256, doi: 10.1007/s11104-010-0639-0.

[35] S. Bittner, N. Legner, F. Beese, E. Priesack, Individual tree branchlevel simulation of light attenuation and water flow of three F. sylvatica L. trees, Journal of Geophysical Research-Biogeosciences 117 (G01037) (2012) 1-17.

[36] M. T. van Genuchten, Closed-form equation for predicting the hydraulic conductivity of unsaturated soils, Soil Science Society of America Journal 44 (5) (1980) 892-898. 
[37] R. A. Feddes, P. Kowalik, K. Kolinska-Malinka, H. Zaradny, Simulation of field water uptake by plants using a soil water dependent root extraction function, Journal of Hydrology 31 (1-2) (1976) 13-26.

[38] N. W. Pammenter, C. Vander Willigen, A mathematical and statistical analysis of the curves illustrating vulnerability of xylem to cavitation, Tree Physiology 18 (8-9) (1998) 589-593.

[39] M. Zeppel, D. Tissue, D. Taylor, C. Macinnis-Ng, D. Eamus, Rates of nocturnal transpiration in two evergreen temperate woodland species with differing water-use strategies, Tree Physiology 30 (8) (2010) 9881000, doi:10.1093/treephys/tpq053.

[40] C. M. O. Macinnis-Ng, S. Fuentes, A. P. O'Grady, A. R. Palmer, D. Taylor, R. J. Whitley, I. Yunusa, M. J. B. Zeppel, D. Eamus, Root biomass distribution and soil properties of an open woodland on a duplex soil, Plant and Soil 327 (1-2) (2010) 377-388, doi:10.1007/s11104-009-0061-7.

[41] C. Macinnis-Ng, M. Zeppel, M. Williams, D. Eamus, Applying a SPA model to examine the impact of climate change on GPP of open woodlands and the potential for woody thickening, Ecohydrology 4 (3) (2011) 379-393, doi:10.1002/eco.138.

[42] I. A. Yunusa, M. J. Zeppel, S. Fuentes, C. M. Macinnis-Ng, A. R. Palmer, D. Eamus, An assessment of the water budget for contrasting vegetation covers associated with waste management, Hydrological Processes 24 (9) (2010) 1149-1158. 
[43] I. A. M. Yunusa, S. Zolfaghar, M. J. B. Zeppel, Z. Li, A. R. Palmer, D. Eamus, Fine Root Biomass and Its Relationship to Evapotranspiration in Woody and Grassy Vegetation Covers for Ecological Restoration of Waste Storage and Mining Landscapes, Ecosystems 15 (1) (2012) 113-127, doi:10.1007/s10021-011-9496-9.

[44] R. F. Carsel, R. S. Parrish, Developing joint probability-distributions of soil-water retention characteristics, Water Resources Research 24 (5) (1988) 755-769, doi:10.1029/WR024i005p00755.

[45] R. H. Froend, P. L. Drake, Defining phreatophyte response to reduced water availability: Preliminary investigations on the use of xylem cavitation vulnerability in Banksia woodland species, Australian Journal of Botany 54 (2) (2006) 173-179.

[46] E. Daly, A. Porporato, I. Rodriguez-Iturbe, Coupled dynamics of photosynthesis, transpiration, and soil water balance. Part I: Upscaling from hourly to daily level, Journal of Hydrometeorology 5 (3) (2004) 546-558.

[47] L. D. Prior, D. Eamus, Seasonal changes in hydraulic conductance, xylem embolism and leaf area in Eucalyptus tetrodonta and Eucalyptus miniata saplings in a north Australian savanna, Plant, Cell and Environment 23 (9) (2000) 955-965, doi:10.1046/j.1365-3040.2000.00612.x.

[48] B. E. Medlyn, R. A. Duursma, D. Eamus, D. S. Ellsworth, I. C. Prentice, C. V. M. Barton, K. Y. Crous, P. De Angelis, M. Freeman, L. Wingate, Reconciling the optimal and empirical approaches to modelling stom- 
atal conductance, Global Change Biology 17 (6) (2011) 2134-2144, doi: 10.1111/j.1365-2486.2010.02375.x.

[49] J. P. Lhomme, E. Elguero, A. Chehbouni, G. Boulet, Stomatal control of transpiration: Examination of Monteith's Formulation of canopy resistance, Water Resources Research 34 (9) (1998) 2301-2308, doi: 10.1029/98WR01339.

[50] R. Allen, M. Smith, L. Pereira, A. Perrier, An update for the calculation of reference evapotranspiration, ICID bulletin 43 (2) (1994) 35-92.

[51] P. G. Jarvis, The Interpretation of the Variations in Leaf Water Potential and Stomatal Conductance Found in Canopies in the Field, Philosophical Transactions of the Royal Society of London. Series B, Biological Sciences 273 (927) (1976) 593-610.

[52] T. Kumagai, Modeling water transportation and storage in sapwood model development and validation, Agricultural and Forest Meteorology 109 (2) (2001) 105-115, doi:10.1016/s0168-1923(01)00261-1.

[53] Y. L. Chuang, R. Oren, A. L. Bertozzi, N. Phillips, G. G. Katul, The porous media model for the hydraulic system of a conifer tree: Linking sap flux data to transpiration rate, Ecological Modelling 191 (3-4) (2006) 447-468, doi:10.1016/j.ecolmodel.2005.03.027. 